\title{
Apicoaortic conduit in a patient with severe aortic stenosis: An alternative to transcutaneous aortic valve implantation
}

\author{
Sotiris C. Stamou, MD, and Nicholas T. Kouchoukos, MD
}

\begin{abstract}
A 90-year-old patient with known coronary artery disease who had mitral valve replacement and coronary artery bypass grafting, as well as repair of his tricuspid valve, 3 years previously presented with increasing shortness of breath. An echocardiogram indicated the presence of severe aortic stenosis (aortic valve area, $0.8 \mathrm{~cm}^{2}$; peak gradient, $50 \mathrm{~mm}$ $\mathrm{Hg}$; and increased velocity through the aortic valve). $\mathrm{He}$ could not walk 100 feet without becoming short of breath and had peripheral edema that was controlled with diuretics. Cardiac catheterization demonstrated patency of 2 saphenous vein grafts to the intermediate branch of the circumflex cor-
\end{abstract}

onary system and distal right coronary artery. He was evaluated for possible percutaneous aortic valve insertion but was not deemed to be a candidate. Because the patient was not considered to be an optimal candidate for repeat sternotomy, he underwent insertion of a left ventricular to descending thoracic aortic bypass conduit containing a 21-mm Medtronic (St Jude Medical, St Paul, Minn) stentless bioprosthesis using cardiopulmonary bypass and hypothermic ventricular fibrillation (Figure 1, A). Postoperative computed tomography demonstrated patency of the conduit (Figure 1, $B)$. The patient is alive and well 1 year after the procedure.

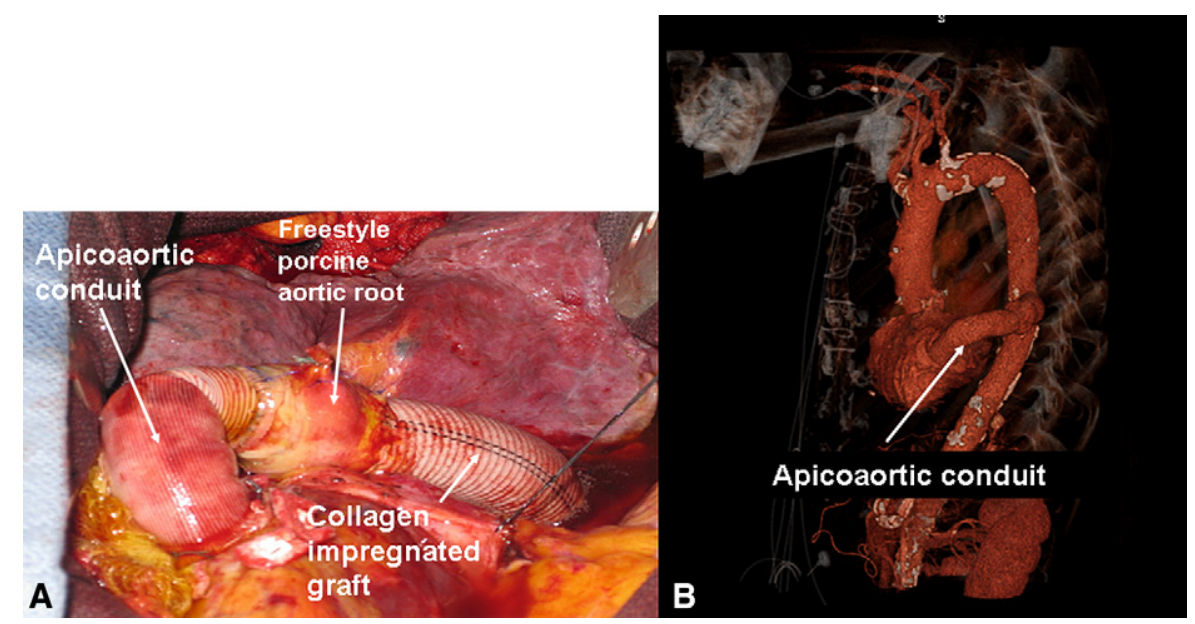

FIGURE 1. A, Intraoperative view of the left ventricular to descending thoracic aortic bypass conduit, the porcine freestyle aortic root, and the collagen impregnated graft from the descending aorta to the porcine root (arrows). B, Computed tomography views with 3-dimensional reconstruction demonstrate patency of the left ventricular to descending thoracic aortic bypass conduit (arrow).

\footnotetext{
From the Division of Thoracic and Cardiovascular Surgery, Missouri Baptist Medical Center, St Louis, Mo.

Disclosures: Authors have nothing to disclose with regard to commercial support.

Received for publication Aug 17, 2010; accepted for publication Aug 25, 2010; available ahead of print Nov 12, 2010.

Address for reprints: Sotiris C. Stamou, MD, 1315 Whispering Pines Dr, Apt L, St Louis, MO 63146 (E-mail: cvsisfun@ @otmail.com).

J Thorac Cardiovasc Surg 2011;141:1538

$0022-5223 / \$ 36.00$

Copyright $@ 2011$ by The American Association for Thoracic Surgery

doi:10.1016/j.jtcvs.2010.08.077
} 